\title{
ALTERAÇÕES MICROBIANAS EM ROCHAS: SOLUBILIZAÇÃO DO FERRO POR AÇÃO DE FUNGOS EM DIABÁSIOS*
}

\author{
REGINA MARIA RIBEIRO**, ADELAIDE MUSSI SANTOS \\ e HEBE LABARTHE MARTELLI***
}

\begin{abstract}
Experimental attack on a mafic rock by a liquid culture of an Aspergillus niger strain isolated from soil, which exhibited a striking solubilizing action upon its iron-containing minerals, was investigated. After 25 days, the iron content of the fungal solutions was 26 times higher than in the sterile control flasks. The microbiological activity was followed by the dry weight of the mycelium, the glucose consumption, the evolution of the total acidity, and the $\mathrm{pH}$ value of the cultures. The kinetics of the iron solubilization of the mycelial growth and the metabolic activity showed significant relationships. The mycelial growth was improved by the presence of the cations extracted from the rock samples. The solubility of iron in these minerals depended on their nature, the surface of attack, and the concentration of the metabolic products; probably all three. Formation of complex could be the mechanism involved, considering that a strong cation exchange-resin was not able to extract iron from the culture solutions.
\end{abstract}

INTRODUÇÃo A idéia de que os microrganismos são importantes nos ciclos de vários elementos na natureza foi expressa por Vinogradskiy, em 1897, (in Waksman, 1952), na sua descoberta dos processos de quimiossinteses. Mais tarde, Vernadskiy (1927; in Waksman, 1952) desenvolveu o estudo da participação dos microrganismos nos processos geológicos, afirmando que esses fenômenos não poderiam realizar-se na ausência de organismos vivos. Porém foi Waksman (1952) que deu ênfase a esses estudos em sua obra clássica Principles of Soil Microbiology. Muitos estudos do papel desempenhado pelos microrganismos em depósito de bleo e minérios sulfetados vêm sendo feitos por cientistas da União Soviética onde se desenvolveu com maior intensidade o estudo do mais novo ramo da Microbiologia, a Geomicrobiologia. O desenvolvimento da Geomicrobiologia como ciência tem sido estreitamente associado com a descoberta do papel desempenhado pelos microrganismos na gênese de vários tipos de depósitos minerais. Apesar disso, relativamente pouco se tem investigado sobre o papel dos seres vivos e seus metabolismos como agentes geoquímicos. Dentre os seres vivos, especial referência deve ser feita aos microrganismos como agentes geoquímicos. São encontrados em praticamente todos os sistemas geoquímicos conhecidos, suportam pressão de $25000 \mathrm{psi}\left(18 \overline{0} 0 \mathrm{~kg} / \mathrm{cm}^{2}\right)$, variação de $\mathrm{pH}$ entre 1,0 e 10,0 , e temperatura de 0 a $75^{\circ} \mathrm{C}$. Alguns crescem em ausência de oxigènio, outros em meio exclusivamente mineral, fixando $\mathrm{CO}_{2}$ em ausência de luz e retirando energia da oxidaçã̃o de elemento e compostos minerais (Kuznetzov et al., 1963).

A utilização da atividade dos microrganismos pelo homem é antiga em certas áreas porém, em Geoquímica, tem sỉdo pouco usado. Dentre as possíveis utilizações que carecem ser desenvolvidas está a aplicação de métodos microbiologicos em prospecção geoquímica, método reconhecido por sua sensibilidade e especificidade.

Outras possíveis aplicações científicas e tecnológicas da participação de ações micro* bianas são: o estudo de alteração das rochas e depósitos minerais; o controle de poluição

* Os resultados que constituem o presente trabalho fazem parte da tese para obtenção do grau de mestre em Geociências, opção Geoquímica, de um dos autores (R.M.R.) e foram apresentados ao V Congresso de Microbiologia, de 21 a 25 de julho de 1974, Rio de Janeiro, RJ

**Instituto de Geociências, Universidade Federal da Bahia, Salvador, BA

***Escola de Química, Universidade Federal do Rio de Janeiro, Rio de Janeiro 
resultante do acúmulo de resíduos minerais, seja industriais, seja de mineração, seja de metalurgia; o tratamento microbiológico de minério e a corrosão.

As pesquisas sobre alterações abordam o estudo das ações mecânicas e químicas. Com freqüência, atenção maior se dá à parte inorgânica das reações químicas. Os microrganismos, porém, desempenham um papel muito importante nos processos de alteração, o que estimula a idéia de estudar a parte orgânica das reações de alteração e tentar extrapolar seus resultados para o campo da lixiviação de minérios. Assim, estar-se-ia aproveitando a energia solar captada, convertida e transportada pelos microrganismos em processos que poderão vir a ser comerciais no futuro.

Este trabalho tem por objetivo apresentar os resultados do estudo da alteração de rochas, feito em laboratório, pela ação de fungos sobre diabásios coletados na região de Salvador. Os fungos desempenham uma função muito importante na alteração das rochas e na dispersão secundária dos elementos: induzem um ambiente ácido resultante de seu metabolismo e agem sobre a matéria orgânica dos solos, transformando-a; elaboram um grande número de enzimas que lhes permitem sobreviver em presença de matéria orgânica dificilmente assimilável por outros microrganismos. Nesse processo, solubilizam vários elementos que liberam das rochas e facilitam sua dispersão.

Em trabalhos anteriores (Ribeiro et al., 1972; Ribeiro, 1974), foi verificado que as espécies do gênero Aspergillus (Aspergillus niger) determinam as transformaçőes mais acentuadas no meio externo.

Descrição do material Como em muitas partes do Estado da Bahia são conhecidas importantes mineralizações associadas a rochas máficas (minérios de cobre, níquel, cromo etc., nas máficas e ultramáficas do embasamento cristalino), selecionou-se para material de estudo uma amostra de um dique de diabásio que corta os granulitos da região de Salvador. A amostra de diabásio, procedente da pedreira Valéria, tem coloração cinzenta-escura-esverdeada, textura fanerítica fina com cristais milimétricos, bem dispersos, de plagioclásio.

As duas primeiras crostas de alteração possuem espessura da ordem de 2 e $4 \mathrm{~cm}$, respectivamente, e uma coloração castanho-amarelada, mais intensa no primeiro estádio que no segundo, e conservam parcialmente a textura original da rocha.

Ao microscópio, o diabásio, examinado por P. V. V. Sá, revelou tratar-se de uma rocha mesocrática de textura subofitica, hipidiomórfica, com a seguinte composição mineralógica, em porcentagem:

$\begin{array}{lr}\text { Plagioclásio } & 41,8 \\ \text { Augita } & 25,7 \\ \text { Quartzo } & 9,2 \\ \text { Biotita } & 4,1 \\ \text { Hornblenda } & 0,9 \\ \text { Clorita } & 8,5 \\ \text { Magnetita } & 9,7 \\ \text { Apatita } & 0,1\end{array}$

O plagioclásio, principal constituinte e determinado pelo ângulo máximo de extinção, mostrou composição $\mathrm{An}_{43}$. Os cristais são subeuédricos e exibem geminação albita e albita-Carlsbad. Por vezes, apresentam-se deutericamente alterados em sericita, epídoto e quartzo.

A amostra de diabásio, com densidade 2,99, apresentou a seguinte composição química: $\mathrm{SiO}_{2}=51,10 \% ; \mathrm{Al}_{2} \mathrm{O}_{3}=13,00 \% ; \mathrm{Fe}_{2} \mathrm{O}_{3}(+\mathrm{FeO})=13,42 \% ; \mathrm{CaO}=8,36 \% ; \mathrm{MgO}=$ 


$$
\begin{aligned}
& =4,67 \% ; \mathrm{MnO}=0,20 \% ; \mathrm{TiO}_{2}=2,36 \% ; \quad \mathrm{Na}_{2} \mathrm{O}=2,74 ; \mathrm{K}_{2} \mathrm{O}=1,15 \% ; \mathrm{H}_{2} \mathrm{O}^{-}= \\
& =3,00 \% ; \mathrm{H}_{2} \mathrm{O}^{+} \text {tr. }
\end{aligned}
$$

MÉTODOS MICROBIOLÓGICOS Foi usada uma cepa de Aspergillus niger isolada do solo de Maragogipe, Bahia, referida em trabalho anterior (Ribeiro et al., 1972).

Os cultivos foram em duplicata, em $150 \mathrm{ml}$ de meio Sabouraud líquido, distribuídos em frascos cônicos de $300 \mathrm{ml}$, mais $10,0 \mathrm{~g}$ da rocha triturada em frações de 1,0 a $2,0 \mathrm{~mm}$. Foi usada como inóculo $(0,5 \mathrm{ml})$ uma suspensão de esporos obtidos por cultivo em tubo de gelose Sabouraud inclinada, a $30^{\circ} \mathrm{C}$ por 7 dias, cillibrada para absorbância de $0,8 \mathrm{em} 570 \mathrm{~mm}$ em fotocolorimetro Linson 3. Os frascos foram incubados em estufa bacteriológica, em repouso a $30^{\circ} \mathrm{C}$, interrompendo-se o cultivo nos intervalos de tempo referidos. O conteudo dos frascos era filtrado em cadinho de Gooch previamente tratado através de papel Whatman n. ${ }^{\circ} 41$ e lavado numerosas vezes com água deionizada. $\mathrm{O}$ volume do filtrado, ajustado ao valor inicial por evaporação a $100^{\circ} \mathrm{C}$, foi usado para as dosagens químicas.

O micélio retido no papel de filtro de Gooch tarado (que inclui também todo o micélio liberado mecanicamente dos fragmentos de rocha que haviam permanecido dentro dos frascos) foi seco a $105^{\circ} \mathrm{C}$ até peso constante.

Descrição mais detalhada das experiências pode ser encontrada em Ribeiro (1974).

Medida do crescimento do fungo 1) Peso seco do micélio; 2) consumo de glicose pela dosagem da glicose residual no meio; 3) variação da acidez e do $\mathrm{pH}$ do meio.

Medida do ataque à rocha Dosagem do ferro solubilizado no meio líquido.

MÉTODOS QUIMICOS E FÍSICOS 1) Dosagem de glicose por método colorimétrico (Nelson, 1944), medida em fotocolorímetro Linson 3; 2) dosagem do íon-ferro por espectrofotometria de absorção atômica, em espectrofotômetro Perkin Elmer modelo 303, equipado com registrador Perkin Elmer modelo 56;3) dosagem de acidez total por alcaiimetria, usando uma solução de hidróxido de sódio $0,025 \mathrm{~N}$ até pH 7, determinado pelo potenciômetro Meter.

RESULTADOS RELAÇÃO ENTRE A GINÉTIGA DA SOLUBILIZAÇÃO DO FERRO E DO GRESCIMENTO DA CULTURA Os dados analíticos representados na Fig. 1 mostram que a solubilização do ferro atinge o máximo aos 25 dias de cultivo. Neste prazo, o teor de ferro no meio líquido, em presença do fungo, é 26 vezes maior que no controle estéril (Tab. I).

Quanto à cinética de solubilização, verifica-se pela curva 2 da Fig. 1 que, no controle estéril, a fase de solubilização do ferro se inicia imediatamente atingindo o máximo em 24 horas. A curva 1 mostra que a fase exponencial da solubilização microbiana só é iniciada no terceiro dia, atingindo o máximo no quinto dia. Isto é explicado observando-se a curva 3 que representa a velocidade de multiplicação do mićlio, a qual atinge o máximo no terceiro dia. Durante este prazo, o ferro extraído é consumido pelo fungo. Cessada a multiplicação do micélio, o teor de ferro em solução aumenta exponencialmente até o $15 .^{\circ}$ dia e apresenta tendência à estabilização até o $25 .^{\circ}$ dia. Entre o $25 .^{\circ}$ e o $30 .^{\circ}$ dia, o teor de ferro em solução decresce. Experiências posteriormente descritas permitiram atribuir o decréscimo a ações complexantes pelos produtos do metabolismo do fungo. A curva 4 representa a velocidade de consumo da glicose, cuja transformação por Aspergillus niger é um processo acidificante (Prescott e Dunm, 1959) que se prolonga além da fase de multiplicação das células, pois estas continuam vivas e consomem energia. Isso sugere que 
Tabela I - Incremento no teor de ferro solubilizado e no peso do micélio

\begin{tabular}{|c|c|c|c|c|}
\hline \multirow{2}{*}{$\operatorname{dias}$} & \multicolumn{4}{|c|}{ milligramas } \\
\cline { 2 - 5 } 1 & $d p^{*}$ & $d p_{1}^{* *}$ & $d X^{* *}$ & $d X_{1}^{* * * *}$ \\
\hline 2 & 0,15 & 0,37 & 20,40 & 10,30 \\
3 & 0,36 & 0,38 & 157,90 & 38,10 \\
4 & 0.56 & 0,39 & 218,60 & 286,60 \\
5 & 1,46 & 0,46 & 77,90 & 2,5 \\
10 & 7,32 & 0,51 & & \\
15 & 9,72 & 0,58 & & \\
20 & 13,17 & 0,64 & & \\
25 & 18,45 & 0,66 & & \\
30 & 16,32 & 0,57 & & \\
\hline
\end{tabular}

*d P, variação do teor de ferro no meio em presença do fungo $* * \mathrm{~d} \mathrm{P}_{1}$, variaça do teor de ferro no controle estéril

$* * * \mathrm{~d} X$, variação do peso do micélio em presença da rocha $/ 24 \mathrm{~h}$

$* * * * \mathrm{~d} \mathrm{X}_{1}$, variação do peso do micélio no controle $/ 24 \mathrm{~h}$

os produtos do metabolismo do fungo têm influência na solubilização do ferro e sugere que este processo continua mesmo quando não mais ocorre multiplicação do agente. A Fig. 2 mostra que nos controles estéreis o $\mathrm{pH}$ e a acidez total variam numa faixa muito estreita. No cultivo controle, em que o fungo cresce em ausência da rocha, o pH decresce continuamente, havendo a formação de ácidos do $2 .^{\circ}$ ao $15 .^{\circ}$ dia.

Notamos que, na presença do diabásio, houve variação do $\mathrm{pH}$ e da acidez total; a velocidade máxima de produção de ácidos é atingida no quarto dia e reduz-se a seguir. A solubilização do ferro prossegue mostrando que não só os ácidos formados mas também outros produtos metabólicos participam do processo. A Fig. 3 mostra que a presença da rocha também influencia o crescimento da cultura, pois o peso do micélio no quinto dia torna-se duas vezes maior no cultivo em que a rocha está presente do que no controle. O mesmo efeito estimulante é observado na velocidade de consumo da glicose, a qual no quinto dia é $50 \%$ maior que no cultivo de controle. Isso pode ser atribuído tanto ao maior teor do cátion ferro no meio quanto à solubilização de outro elemento ativante, presente na amostra, pois é conhecido que cobre, zinco e manganês estimulam o Aspergillus niger (Nicholas, 1957), tendo sido por nós verificada a ação estimulante do níquel (Ribeiro et al., 1969). Também a produção de ácidos e a variação do $\mathrm{pH}$ são modificadas pela presença da rocha, como pode ser visto na Fig. 2, respectivamente, nas curvas 6 e 7 (acidez) e 3 e $4(\mathrm{pH})$.

INFLUENGIA DA SUPERFIGIE DE ATAQUE DA ROCHA Amostras com diferentes frações granulométricas $(10,0 \mathrm{~g})$ foram adicionadas a $150 \mathrm{ml}$ de meio Sabouraud 


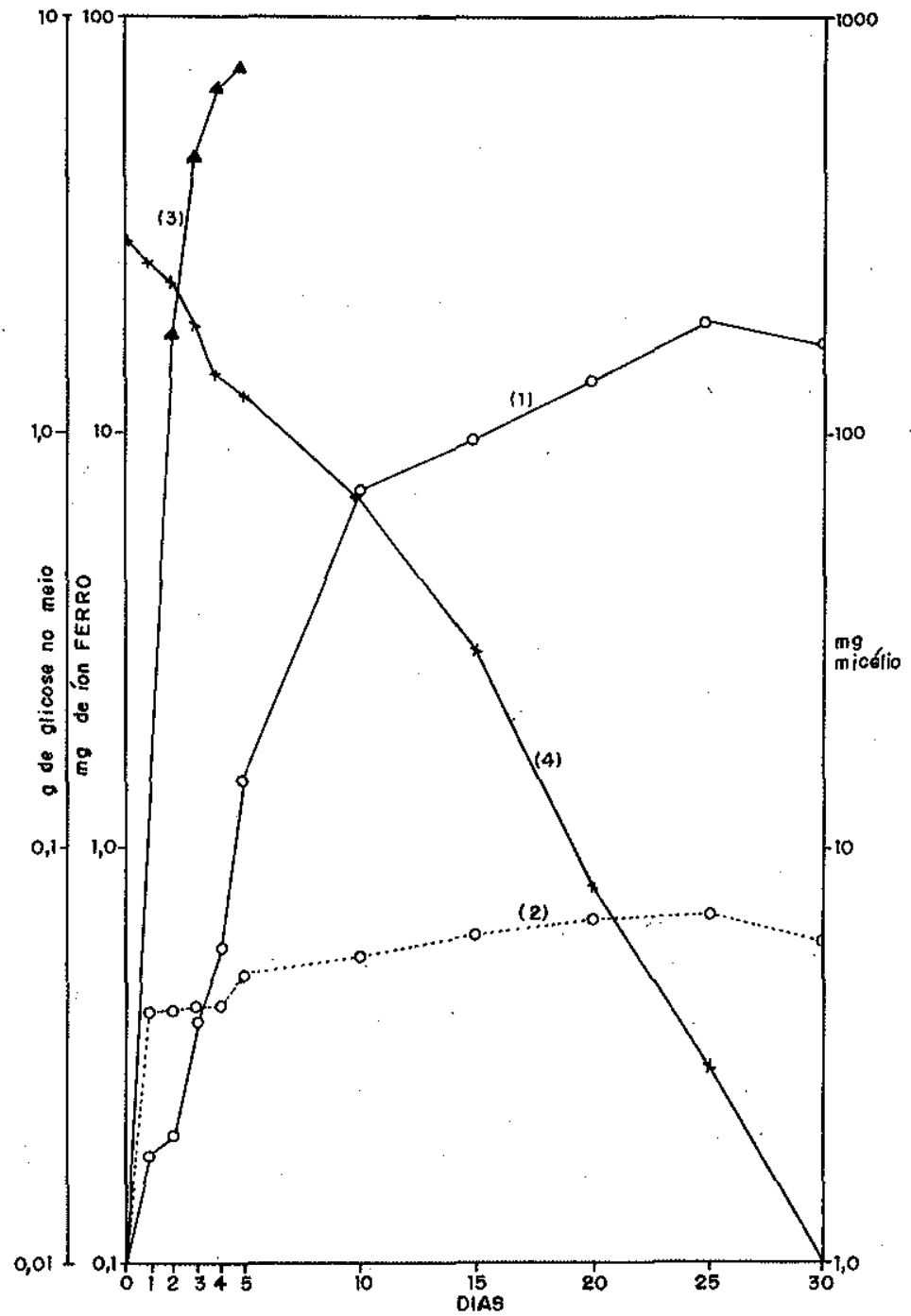

Figura 1 - Ginética da solubilização do ferro. Curva 1: solubilização microbiana do ferro; curva 2: controle estéril; curva 3 : peso seco do micélio; curva 4: cuisumo de glicose

líquido semeado, cultivado a $30^{\circ} \mathrm{C}$ por 25 dias, e tratadas como foi acima descrito. Os resultados estão mostrados na Tab. II. Como pode ser visto, o teor de ferro inicial nas amostras varia conforme a fração granulométrica, o que pode ser atribuído à distribuição irregular dos minerais na rocha e às pequenas dimensões da amostra. Conforme costuma ocorrer, a porcentagem de solubilização é maior nas frações de menores dimensões, ou seja, a solubilização aumenta com a superficie de ataque. Uma anomalia ocorre na fração estudada de menor granulometria $(<0,053 \mathrm{~mm})$ apesar de ter o mais alto teor inicial de ferro. $O$ fato de a porcentagem da solubilização do ferro na fração de granulometria $<0,053 \mathrm{~mm}$ ter sido menor que na fração de granulometria $0,053-0,250 \mathrm{~mm}$ é atribuído à irregularidade da distribuição dos minerais de ferro atacáveis que acreditamos presentes em maior proporção na fração mais grossa $(0,053 \mathrm{a} 0,250 \mathrm{~mm})$. 


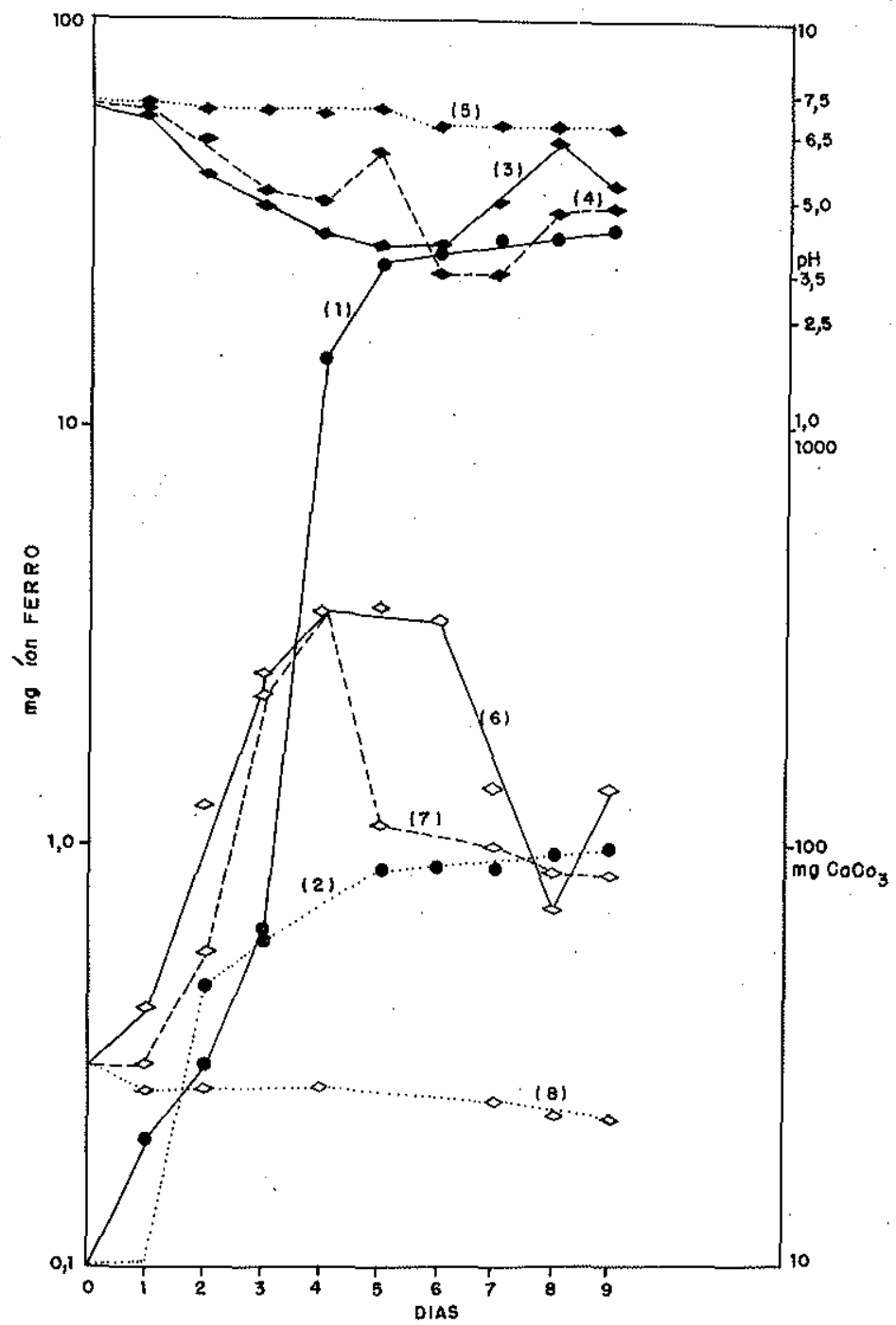

Figura 2 - Cinética da solubilização do ferro e da variação da acidez total e do pH. Curva 1: solubilização microbiana do ferro; curva 2: controle estéril; curva $3: \mathrm{pH}$, cultura com rocha; curva 4: $\mathrm{pH}$, controle sem rocha; curva 5 : controle estéril; curva 6 : acidez total, cultura com rocha; curva 7 : acidez total, controle sem rocha; curva 8: acidez total, controle estéril

PODER GOMPLEXANTE DOS PRODUTOS DO METABOLISMO DO FUNGO A capacidade de complexante dos produtos metabólicos de Aspergillus niger relativamente ao íon ferro foi estudada em cultura análoga às anteriores, incubadas a $30^{\circ} \mathrm{C}$ por 25 dias; o sobrenadante foi então filtrado, conforme foi descrito. Para as determinações, foi adaptada a marcha descrita por Arrieta e Grez (1971): 10, 20 e $30 \mathrm{ml}$ do filtrado foram colocados em frascos cônicos de $125 \mathrm{ml}$ e adicionados de $5,0 \mathrm{ml}$ de uma solução-padrão de nitrato férrico, contendo $5 \mu \mathrm{g} / \mathrm{ml}$ de cátion férrico, e de mais $5 \mathrm{ml}$ de uma solução $2 \mathrm{~N}$ de $\mathrm{KNO}_{3}$ $O$ volume final da amostra foi completado para $50 \mathrm{ml}$ com água deionizada.

As soluções foram deixadas em repouso por 16 horas e o ferro total em cada frasco 


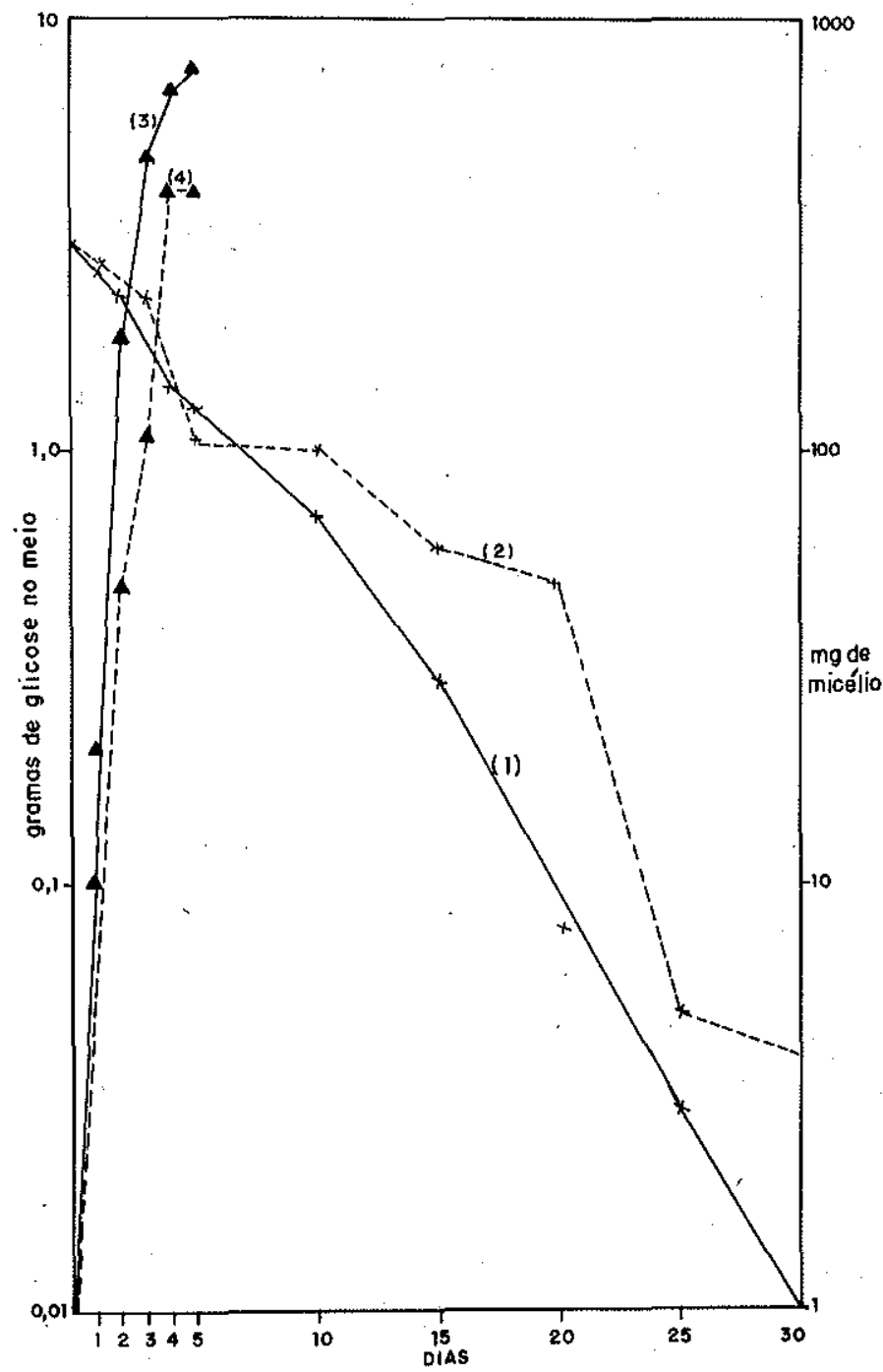

Figura 3 - Influência da rocha na cultura. Curva 1 : consumo de glicose, cultura com rocha; curva 2: consumo de glicose, controle; curva 3: peso seco de micélio, cultura com rocha; curva 4: controle

foi determinado por absorção atômica. Em seguida, adicionaram-se a cada frasco $200 \mathrm{mg}$ de resina cationica (Dowex $50 \times 820 / 50 \mathrm{mesh}$ ) e os frascos foram agitados por 4 horas. A resina foi separada por filtração, determinando-se no filtrado a quantidade de ferro residual e o valor do $\mathrm{pH}$. Um controle foi feito com $5 \mathrm{ml}$ da solução-padrão e mais $5 \mathrm{ml}$ da solução $\mathrm{KNO}_{3}$ e outro com solução-padrão contendo $50,0 \mu \mathrm{g}$ de íon ferro/ml, teor que corresponde ao da amostra contendo a mais elevada concentração de íon ferro.

Os resultados estão apresentados na Tab. III. Como pode ser visto pelos dados apresentados, na ausência dos produtos metabólicos resultantes da atividade microbiana, a resina absorveu $100 \%$ do ferro das amostras. Em presença desses, porém, a porcentagem de absorção desceu para 17\%. Pode-se dizer que o ion ferro na cultura de fungo está complexado na proporção média de $83 \%$. 
DISCUSSÃo A cinética da solubilização microbiana do ferro (Fig. 1) obedece ao modelo característico dos processos bioquímicos (cinética tipo Michaelis). $O$ fato de o teor de ferro no meio continuar aumentando (Tab. I) depois de cessada a multiplicação do micélio caracteriza a solubilização microbiana como um processo não-associado ao crescimento da rultura (Aiba et al., 1973).

Por outro lado, a fase exponencial do consumo de glicose se inicia depois que a multiplicação do micélio atinge a fase estacionária, o que sugere ser a solubilização do ferro, nesta fase, mais estreitamente relacionada ao metabolismo da glicose pelo micélio. E nesta fase também que a velocidade de extração é maior (Tab. I), mostrando que os produtos do metabolismo secundário do fungo são efetivamente os fatores mais importantes do ataque à rocha. No caso da variação do $\mathrm{pH}$ e da acidez total do meio, as curvas da Fig. 2 sugerem que a ação do fungo, embora evidente, não é direta. Esta observação aumenta a importancia do processo dá ação complexante dos produtos metabólicos do fungo (Tab. II), efeito tão forte que sobreleva a ação da resina cátion permutante ensaiada. É possível que a variação do $\mathrm{pH}$ e da acidez total altere a solubilização do ferro por favorecer a referida ação complexante. É interessante notar que os componentes extraídos da rocha, por sua vez, estimulam o crescimento da cultura e o metabolismo da glicose (Fig. 3), logo a formação dos produtos metabólicos que os complexam. As anomalias relativas à influência de distribuicão dos componentes mineralógicos da rocha em sua alteração superficial

Tabela II - Fraçð̃es granulométricas e solubilização microbiana do ferro

\begin{tabular}{|c|c|c|c|c|c|}
\hline \multirow{2}{*}{$\begin{array}{l}\text { Fracäo } \\
\text { Gronulo- } \\
\text { métrica } \\
\text { mm }\end{array}$} & \multicolumn{4}{|c|}{ mg íon ferro solubilizado } & \multirow{2}{*}{$\begin{array}{c}\% \\
\text { Solubili- } \\
\text { zoçöo }\end{array}$} \\
\hline & iniciol & $A^{*}$ & $c^{*}$ & $\Delta$ & \\
\hline$<0,053$ & 1,00 & 17,90 & 1,42 & 16,48 & 1,65 \\
\hline $0,053-0,063$ & 0,93 & 24,90 & 3,80 & 21,10 & 2,11 \\
\hline $0,063-0,125$ & 0,91 & 21,20 & 2,60 & 18,60 & 1,96 \\
\hline $0,125-0,250$ & 0,95 & 20,80 & 2,50 & 18,30 & 1,83 \\
\hline $0,250-0,500$ & 0,99 & 17,80 & 1,80 & 16,00 & 1,61 \\
\hline $0,500-1,00$ & 0,91 & 16,80 & 0,62 & 16,17 & 1,61 \\
\hline $1,00-2,00$ & 0,90 & 15,60 & 0,37 & 15,23 & 1,52 \\
\hline $2,00-2,50$ & 0,89 & 13,30 & 0,31 & 12,98 & 1,30 \\
\hline $3,50-4,00$ & 0,92 & 11,20 & 0,26 & 10,94 & 1,09 \\
\hline $4,00-5,00$ & 0,93 & 10,70 & 0,24 & 10,46 & 1,05 \\
\hline
\end{tabular}

${ }^{*} \mathrm{~A}-$ meio de cultura + rocha $+\mathrm{A}$ - niger; ${ }^{*} \mathrm{C}-$ meio de cultura + rocha; $\Delta-$ solubilização microbiana. Meio Sabouraud líquido, cultivo ao ar, em repouso, $30^{\circ} \mathrm{C}, 25$ dias. 
Tabela HII - Adsorção do ferro por resina trocadora*

\begin{tabular}{|c|c|c|c|c|c|c|}
\hline \multicolumn{2}{|l|}{ Soluçōo } & \multicolumn{4}{|c|}{$\mu g$ de ferro/ml da solução } & $\%$ Ferro absor - \\
\hline Ensaio & $\mathrm{ml}$ & $\begin{array}{l}\text { Antes da } \\
\text { adição do } \\
\text { resina }\end{array}$ & $\mathrm{pH}$ & $\begin{array}{l}\text { Depois da } \\
\text { adigão da } \\
\text { resina }\end{array}$ & $\mathrm{pH}$ & $\begin{array}{l}\text { vido pela re- } \\
\text { sino }\end{array}$ \\
\hline Padrão $x x$ & 50 & 0,55 & 4,2 & 0,00 & 2,5 & 100,0 \\
\hline Controle $t$ & 50 & 55,00 & 1,1 & 0,00 & & \\
\hline Meio de $t t$ & 10 & 0,03 & 5,0 & 0,00 & 3,0 & 100,0 \\
\hline culturo & 20 & 0,13 & 5,0 & 0,00 & 3,2 & 100,0 \\
\hline & 30 & 0,16 & 5,0 & 0,00 & 3,3 & 100,0 \\
\hline Meio mois & 10 & 0,54 & 4,0 & 0,00 & 2,0 & 100,0 \\
\hline padrõo & 20 & 1,10 & 4,5 & 0,00 & 2,2 & 100,0 \\
\hline & 30 & 1,65 & 4,0 & 0,00 & 2,3 & 100,0 \\
\hline Filtrado & 10 & 0,90 & 3,5 & 0,00 & 1,9 & 100,0 \\
\hline mais podrão & 20 & $i, 90$ & 3,5 & 0,00 & 2,0 & 100,0 \\
\hline & 30 & 2,80 & 3,5 & 0,00 & 2,0 & 100,0 \\
\hline Meio mais & 10 & 0,60 & 4,5 & 0,00 & 2,7 & 100,0 \\
\hline rocha & 20 & 1,25 & 4,3 & 0,00 & 2,6 & 100,0 \\
\hline & 30 & 1,90 & 4,2 & 0,00 & 2,5 & 100,0 \\
\hline Meio & 10 & 1,03 & 4,0 & 0,00 & 2,0 & 100,0 \\
\hline mais rocha & 20 & 2,08 & 3,8 & 0,00 & 2,0 & 100,0 \\
\hline mais padrão & 30 & 3,10 & 3,8 & 0,00 & 2,1 & 100,0 \\
\hline Filtrodo & 10 & 15,25 & 4,5 & 13,00 & 2,7 & 14,7 \\
\hline sem padräo & 20 & 30,60 & 4,6 & 26,00 & 2,7 & 15,0 \\
\hline & 30 & 46,00 & 4,6 & 40,00 & 2,6 & 13,0 \\
\hline Filtrado & 10 & 15,70 & 4,0 & 13,00 & 2,0 & 17,2 \\
\hline mais padrõo & 20 & 31,50 & 4,2 & 25,50 & 22 & 19,0 \\
\hline & 30 & 47,20 & 4,2 & 40,00 & 2,2 & 15,2 \\
\hline
\end{tabular}

*Resina Dowex $50 \mathrm{~W}-\mathrm{X} 820 / 50$ mesh

$\mathrm{xx} 25 \mu \mathrm{g}$ de ferro como nitrato férrico, $5 \mathrm{ml}$ de $\mathrm{KNO} 32 \mathrm{~N}$, água deionizada para volume final de $50 \mathrm{ml}$.

$\lceil 50 \mu \mathrm{g} / \mathrm{ml}$ de ferro iônico, em solução padrão de nitrato férrico.

$\dagger \dagger$ meio Sabouraud líquido, cultura ao ar $30^{\circ} \mathrm{C} / 25$ dias. 
(Tab. II) sugeriram que a pesquisa se desdobrasse no estudo da ação microbiana sobre os próprios minerais isolados, o que está sendo feito.

CONCLUSÓES 1. Os resultados encontrados mostram uma nítida e significativa ação do Aspergillus niger sobre o diabásio, com solubilização crescente do ferro, que atingiu um máximo entre 25 e 30 dias. Admitindo-se que em ambiente fechado o teor máximo de ferro que o fungo tolera foi alcançado, a liberação de maior proporção do elemento só seria possível com a remoção do soluto, ou precipitação do ferro, e substituição por solvente novn.

2. A ação do fungo sobre a rocha não é direta, mas resulta dos produtos do metabolismo, como se deduz dos resultados relacionados na Tab. III.

3. A cinética da extração microbiana do ferro seguiu o modelo clássico tipo Michaelis (Fig. 1).

4. A cinética do consumo de glicose confirma que o produto de seu metabolismo pode influir na solubilização do ferro. Porém, nota-se que a solubilização do ferro prossegue até mais rapidamente quando a concentração de glicose torna-se muito diminuta, quase ausente do meio (Fig. 1).

5. O ferro iônico liberado dos minerais forma com os produtos metabólicos do fungo um complexo organometálico. Na ausência dos produtos metabólicos resultantes da atividade microbiana, a resina absorveu $100 \%$ do ferro das amostras. Pode-se dizer que o ín ferro na cultura contendo a rocha está complexado na proporção de $83 \%$ (Tab. III).

Agradecimentos Este trabalho contou com o auxílio das seguintes instituições: Coordenação de Aperfeiçoamento de Pessoal de Nivel Superior, Conselho Nacional de Pesquisas, Ministério do Planejamento, Superintendência para o Desenvolvimento do Nordeste, Banco Nacional de Desenvolvimento Econômico e faz parte de uma das linhas de pesquisa do Projeto de Geoquímica da UFBa.

Agradecimentos especiais são devidos ao Prof. Sylvio de Queirós Mattoso pelo trabalho de revisão e discussão do texto.

\section{BIBLIOGRAFIA}

AIBA, S., HUMPHREY, A. E. e MILLES, N. F. - 1973 - Biochemical Engineering, University of Tokio Press, Tóquio

ARRIETA, L. e GREZ, R. - 1971 - Solubilization of iron-containing minerals by soil microorganism. Applied Microbiology 22: $487-490$

KUZNETSOV, S. I., IVANOV, M. V. e LYALYKOVA, S. N. - 1963 - Geological Microbiology, McGraw-Hill Book Co., New York.

NELSON, A. - 1944 - Determination of reducing sugars. J. Biol. Ghem. 153: 375-385,

NIGHOLAS, D. J. D. - 1957 - Microbiological methods of determining magnesium, iron, copper, zinc, manganese and molybdenium, in Colowick, S. P. e Kaplan, N. O. (eds.), Methods of Enzymology

PRESGOTT, C.S. e DUNN, G. G. - 1959 - Industrial Microbiology. McGraw-Hill Book Co., New York

RIBEIRO, R. M. - 1974 - Alteração por fungos de minerais contendo ferro. Tese de Mestrado. Instituto de Geociencias, Universidade Federal da Bahia, Salvador, Bahia (inédito)

RIBEIRO, R. M., MARTELLI, H. L. e ROSEMBERG, J. A. - 1969 - Dosagem microbiológica do níquel em amostras de solo. Rev. Bras. Farmácia 3: 73-75

RIBEIRO, R. M., MARTELLI, H. L. e SANTOS, A. M. - 1972 - Estudo da flora microfúngica de uma área mineralizada de cobre, Maragogipe, BA. Rev. Microbiol. 3; 147-152 